Федотов В.Г., Мixeєв O.I.

\title{
ВПЛИВ ЕЛЕКТРИЧНО АКТИВНИХ ДЕФЕКТІВ НА ТЕРМОСТИМУЛЬОВАНІ СТРУМИ В КРИСТАЛАХ ДИФОСФІДУ ЦИНКУ
}

У статті проведено дослідження щодо впливу електрично активних дефектів на термостимульовані струми в кристалах дифосфіду ичнку. Відомо, що зростання електропровідності у напівпровідникових матеріалах відбувається двома шляхами: за рахунок підвищення їх температури, а також через зріст кількісті домішок та дефектів у кристалах ичих матеріалів. 3 иієї точки зору до перспективних напівпровідникових матеріалів можна віднести кристали дифосфіду иинку та кадмію. У нашому випадку у якості об'єкту дослідження були обрані кристали $\alpha-\mathrm{ZnP}_{2}$. У тетрагональних кристалах дифосфіду изинку, які були вирощені методом сублімації у двох температурній печі, виявлені електрично активні дефекти, щзо обумовлюють появу релаксаційних струмів короткого замикання у процесі нагріву. Спонтанна поляризачія, щзо генерує термостимульовані струми короткого замикання, викликана порушеннями динамічної рівноваги в електронній та гратковій підсистемах кристалу $\alpha-\mathrm{ZnP} \mathrm{P}_{2}$

Наведено, щзо динамічна рівновага між електронною та гратковою пілсистемами визначає характер змін властивостей напівпровідникових кристалів. У свою чергу, зміна ж швидкості у прочесах нагрівання безсумнівно приводитимо до порушення динамічної рівноваги між иими підсистемами та, отже, $i$ до появи термостимульованих струмів. У ході дослідження виявлена здатність ичих кристалів утворювати спонтанну поляризацію, яка приводить до появи термостимульованих струмів короткого замикання у напрямку (001). Це явище обумовлено не фазовими температурними переходами, як уявлялося раніме, а, найімовірніме, у результаті домішкових викривлень кристалічної гратки при ї̈ нагріві, які призводять до порушення динамічної рівноваги у електронній та гратковій підсистемах кристалу за рахунок появи електрично активних дефектів.

Ключові слова: пониженні симетричні кристали, електрично активні дефекти, термостимульовані струми.

Постановка проблеми. Питання освоєння технологій сучасних електронних напівпровідникових засобів мають дуже велике значення. Одним 3 ефективних напрямів у цієї сфері є дослідження нових властивостей деяких природних кристалів. До таких перспективних кристалів відносяться тетрагональні кристали дифосфідів цинку та кадмію $\left(\mathrm{ZnP}_{2}\right.$ та $\left.\mathrm{CdP}_{2}\right)$ - речовин 3 пониженою симетрією стосовно просторового розташування кристалічних зв'язків. В них можна виділити дві слабко зв'язані між собою підсистеми атомів: підсистему атомів $\mathrm{P}$ та більш рухому підсистему атомів $\mathrm{Zn}$ i Cd. У таких кристалах можна очікувати суттєві зміни у відомих фізичних процесах, полегшення фазово-структурних та поліморфних перетворень, появи нових ефектів, що можуть бути використані у електронній промисловості. Зокрема в цих кристалах при взаємодії електрично активних дефектів можуть утворюватися сторонні сили, що сприяють появі термостимульованих струмів провідності (ТССП). 
Формулювання цілі статті. Відомо [1,2], що при вирощуванні монокристалів $\mathrm{ZnP}_{2} 3$ парової фази при неконтрольованому парціальному тиску компонентів одержуються зразки з певною концентрацією власних дефектів, які утворюють різні рівні у забороненій зоні цих напівпровідників.

У нашому випадку монокристали дифосфіду цинку вирощувались методом сублімації в двох температурній печі із полікристалічної речовини. При цьому метою досліджень було встановлення природи виникнення термостимульованих струмів у кристалах $\mathrm{ZnP}_{2}$ тетрагональної модифікації, які надалі можуть бути струмами провідності (ТССП) та струмами короткого замикання (ТССКЗ).

Матеріали основної частини. На рис. 1 (криві 1,2 ) показані спектри ТССП для двох зразків дифосфіду цинку $\left(\mathrm{ZnP}_{2}\right)$, які належать одній партії, що одержана саме методом сублімації. Криві зняті при однакових експериментальних умовах. 3 врахуванням логарифмічному масштабу по осі ординат видно, що концентрації заповнених пасток цих зразків суттєво розрізняються. 3'ясування природи максимумів ТССП здійснювалось шляхом їх термічної очистки, а також методом їх порівняння зі спектрами термостимульованих струмів короткого замикання (ТССКЗ) у цих зразках.

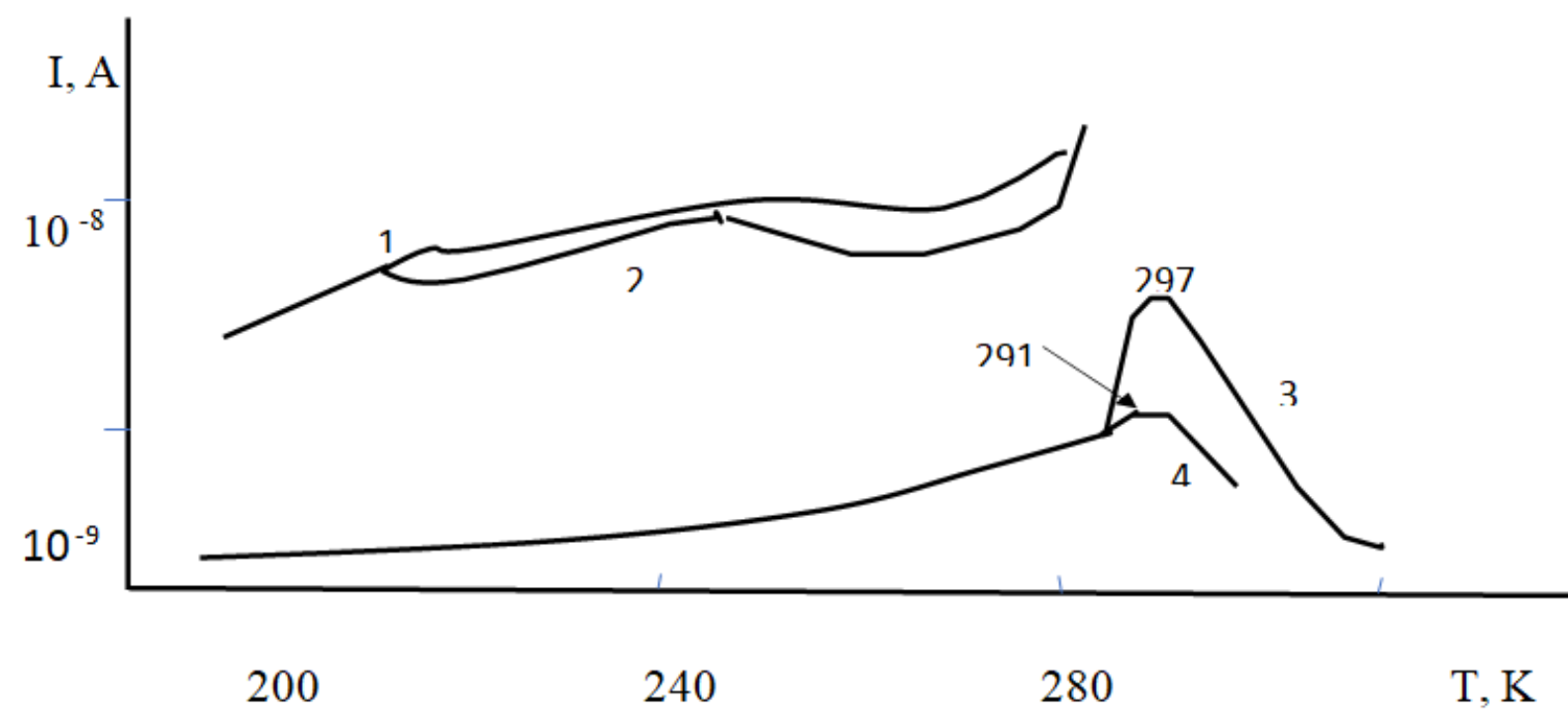

Рисунок 1 - Спектри ТССП (криві 1,2) та спектри ТССКЗ (криві 3, 4) для двох зразків кристалів $\alpha-\mathrm{ZnP}_{2}$ з однієї партії

У результаті вимірювання термостимульованих струмів провідності в режимах послідовного термічного очищення максимумів (рис. 2) встановлені квазідискретні енергетичні рівні пасток з $\mathrm{W}=(0,35 \pm 0,01) \mathrm{eB}$ та $0,47 \pm 0,01 \mathrm{eB}$, які відповідають за максимуми струму у області $200 \ldots 280 \mathrm{~K}$.

Третій рівень $з$ енергією 0,58 еВ отриманий екстраполяцією кривої ТССП у інтервалі температур 280...300 К. Коректне визначити третій рівень вдалося тільки за результатами ТССКЗ (див. рис.1, криві 3, 4), які були зняті при різних швидкостях нагрівання. Спосіб зміни швидкості нагрівання дозволив визначити енергію активації електрично активних дефектів по нахилу залежності величини максимуму піку термостимульованого струму від температури цього максимуму. Якщо обмежитись 
лише двома швидкостями нагріву, то енергію активації електрично активних дефектів можна розрахувати за формулою [2]

$$
W=\frac{k T_{m 1} \cdot T_{m 2}}{T_{m 1}-T_{m 2}} \cdot \ln \frac{\beta_{1} T_{m 2}^{2}}{\beta_{2} T_{m l}^{2}}
$$

де $\kappa$ - постійна Больцмана;

$T_{m 1}$ - температура першого максимуму, К;

$T_{m 2}$ - температура другого максимуму, К;

$\beta_{1}$ - коефіцієнт швидкості нагріву при досягненні температури $T_{m 1}$;

$\beta_{2}$ - коефіцієнт швидкості нагріву при досягненні температури $T_{m 2}$.

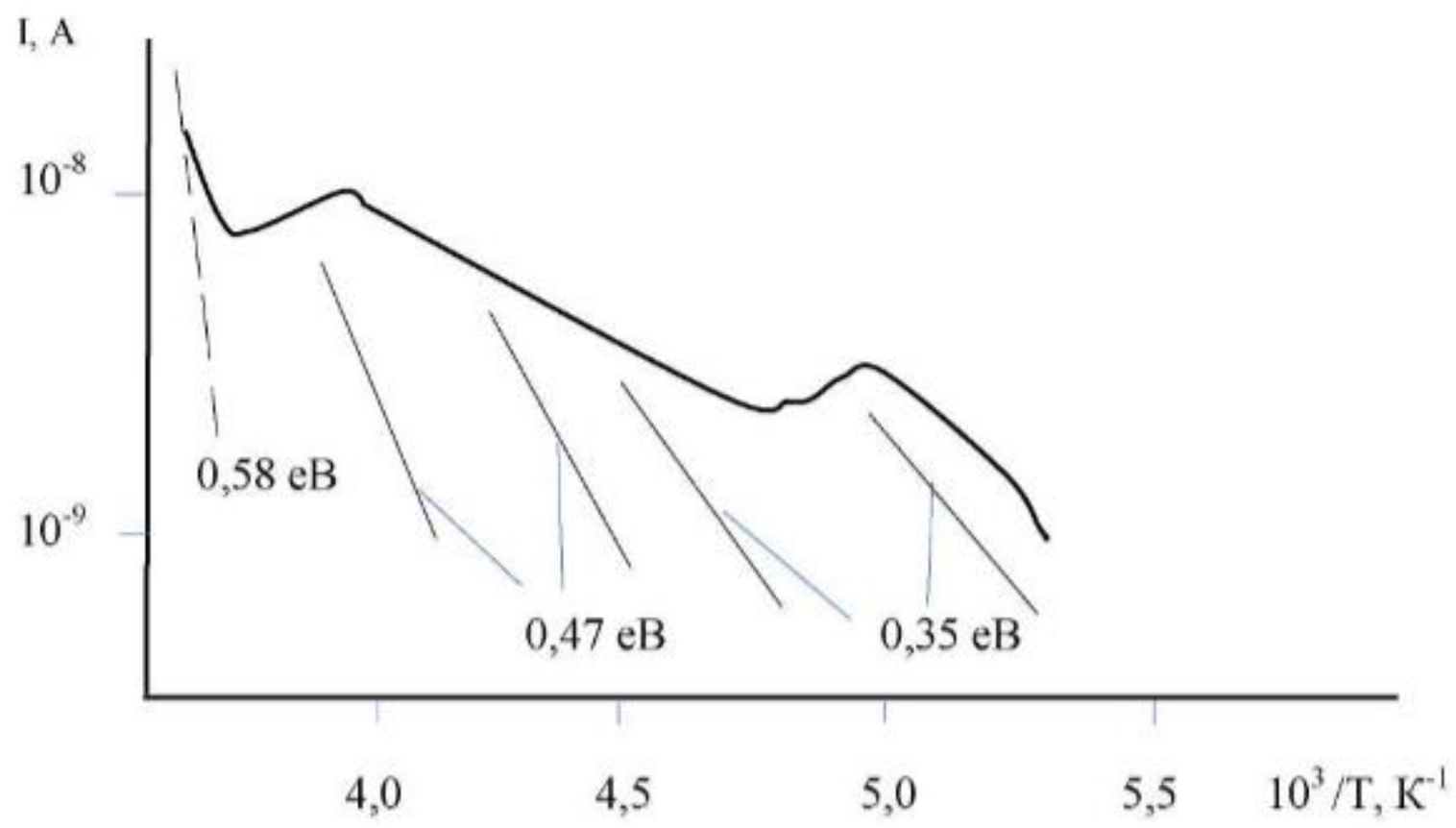

Рисунок - 2 Термічна очистка кривої ТССП в монокристалах $\alpha-\mathrm{ZnP}_{2}$

Розрахунки за формулою (1) дають значення енергії активації 0,6 еВ. Енергія активації електрично активних дефектів здійснює вплив не лише на температурне положення піку термостимульованого струму, а також на температурну «ширину» цього піку. Таким чином, можна поставити обернену задачу - визначити енергію активації дефектів кристалу по температурній залежності ширини відповідного піку термостимульованого збудження за способом парціальної напівширини піку [2]. Суть цього способу полягає у тому, що по кривій ТССКЗ поряд з температурою максимуму визначаються низькотемпературна $(\Delta \mathrm{T}-)$ та високотемпературна $(\Delta \mathrm{T}+)$ напівширини піку, тобто інтервал температур, у межах якого термостимульовані струми більша або дорівнюють половині свого максимального значення.

При кінетиці релаксаційного процесу слабкого перезахвату у зоні високотемпературної напівширини піку енергія активації буде дорівнувати

$$
W=\frac{k T_{m}^{2}}{\Delta T+}
$$


а при кінетиці релакційного процесу сильного перезахвату у тій же зоні енергія активації вже буде рівна:

$$
W=\frac{2 k T_{m}^{2}}{\Delta T+}
$$

Формули (2 і 3 ) свідчать про те, що високотемпературна напівширина ТССКЗ може змінюватись у два рази при зміні кінетики релаксаційного процесу.

Якщо врахувати вплив кінетики релаксаційного процесу на величину енергії активації, то найкраща згода одержується тільки при сильном перезахваті - коли практично всі звільнені носії заряду знову захоплюються пастками. Так як максимуми ТССКЗ при температурі 297К мають характерну асиметрію низькотемпературної та високотемпературної напівширини піку, то це свідчить, що процес пройшов при сильном перезахваті.

За формулою (3) енергія активації електрично активного рівня дорівнює $0,62 \pm 0,01$ еВ. Цей рівень, мабуть, може бути пов'язаний зі власними дефектами та їх комплексами. Раніше за вимірюванням температурної залежності дірок був встановлений акцепторний рівень $\mathrm{E}_{\mathrm{v}}+(0.4+0,05) \mathrm{eB}$ [3]. У роботі [4] 3 аналогічної залежності одержаний акцепторний рівень $\mathrm{E}_{\mathrm{v}}+(0.5+0,05) \mathrm{B}$. При дальнійших дослідженнях були встановлені і більш глибокі рівні енергії активації з величинами $\mathrm{E}_{\mathrm{v}}$ +0.62 та $\mathrm{E}_{\mathrm{v}}+0.85 \mathrm{eB}$, які пов'язуються із винекненням неконтрольованих дефектів та їх комплексів, що складаються з акцептора - двохкратно іонізованої вакансії катіона та донора у вузлах фосфору..

А тепер обговоримо можливу природу сторонніх сил у кристалах $\alpha-\mathrm{ZnP}_{2}$, які приводять до виникнення релаксаційних струмів. Ці струми фіксувались на зразках у напрямку [001] тетрагонального фосфіду цинку. Максимум струму ( $\left.=10^{-9} \mathrm{~A}\right)$ спостерігався при температурі 297К, при цьому час спаду складав декілька годин у залежності від швидкості нагрівання. Треба відзначити, що реласаційні струми можуть виникати не тільки у кристалах без центра симетрії, а і у центросиметричних зрізках.

На данний час у наукової літературі запропоновано декілька моделей сторонніх сил у твердих діелектриках та напівпровідниках [5]:

- модель макроскопічно неоднорідного середовища (так звана, концентраційна ЕРС);

- дифузія домішкових іонів та їх хімічна взаємодія з компонентами середовища;

- зміщення центру тяжіння електронного пакету у наслідок анігіляції дефектів у середовищах без центру симетрії;

- анігіляція пар «вакансія - міжвузольний атом» у зрізках без центру симетрії.

Всі перелічені моделі не пов'язані зі змінами у кристалах спонтанної полярізації, тому термостимульовані струми, які можуть виникати при нагріві таких об'єктів, не обумовлені піроелектричними явищами.

А тепер перейдемо до розгляду струмів, що виникають при нагріванні, яке обумовлено піроелектричними явищами. Перш за все, треба зауважити, що піроелектричні властивості не характерні для класу симетрії $\mathrm{D}_{4}$ головної гратки кристалів $\alpha$ - $\mathrm{ZnP}_{2}$. Однак, як показали рентгенографічні дослідження [6], була виявлена послідовність фазових переходів, що пов'язані з процесами перетворення несумірній структурі з хвильовим вектором модуляції:

де $\delta=0,047$ при Т $=293 К$;

$$
\boldsymbol{q}=\boldsymbol{\delta} \cdot \boldsymbol{c}
$$


c - постійна гратки.

Також були визначені мікроструктурні фази з більшим порядком сумірності, у створенні яких, можливо, прийняли участь не самі кристалічні гратки, а їх дефекти. Відмітимо, що максимуми на залежності I(T) відповідають інтервалу зміни доменних стінок, а різкий спад температури є наслідком руйнування цих стінок. На підставі моделі Френкеля - Канторової зруйновані граткові мікрооб'єми з присутністю дефектів можуть предсталяти собою протяжні просторові утворення, що обов'язково містять надлишкові іоні або діркі. Саме тому їх рух у кристалі при нагріванні може забеспечити перенос заряду [7], при цьому швидкість нагріву визначає величину термостимульованого струму. Так, було встановлено, що, зменьшуючи швидкість нагріву у 3 рази, максимум на залежності I(T) зміщується у область низьких температур, тобто величина струму зменшувалась у двічі (див. рис. 1, криві 3,4 ).

Можна припустити, що зміщення максимуму на залежності I(T) при малих швидкостях нагрівання обумовлено порушенням динамічної рівноваги у електронній та гратковій підсистемах кристалу $\alpha-\mathrm{ZnP}_{2}$.

Відомо [4], що реласація носіїв струму з глибоких рівнів прилипання може протікати достаньо довго. У цієї же роботі показано, що динамічна рівновага між електронною та гратковою пілсистемами визначає характер змін властивостей напівпровідникових кристалів. У свою чергу, зміна ж швидкості у процесах нагрівання безсумнівно приводитимо до порушення динамічної рівноваги між цими підсистемами та, отже, i до появи термостимульованих струмів. Підтвердженням цього $є$ дилатометрічні дослідження, які проведені у роботі [8] у достатньо широком діапазоні температур 290...720K на кристалах $\alpha-\mathrm{ZnP}_{2}$.

Висновки: Таким чином, по спектрам ТССП та ТССКЗ у тетрагональних кристалах $\alpha-\mathrm{ZnP}_{2} 3$ домішковою провідністю встановлені відповідні рівні енергії активації із потужностями у $0,35 \mathrm{eB}, 0,47 \mathrm{eB}$ та $0,58 \mathrm{eB}$. Виявлена здатність цих кристалів утворювати спонтанну поляризацію, яка приводить до появи термостимульованих струмів короткого замикання у напрямку (001). На нашу думку, це явище обумовлено не фазовими температурними переходами, як уявлялося раніше [8], а, найімовірніше, у результаті домішкових викривлень кристалічної гратки при ії нагріві, які призводять до порушення динамічної рівноваги у електронній та гратковій підсистемах кристалу за рахунок появи електрично активних дефектів.

\section{ЛIТЕРАТУРА}

1. Горбань И.С. и др. Уровни прилипания в кристаллах дифосфида цинка тетрагональной модификации.// ФТПА, 1978. т.12. вып. 2. С. 410-413.

2. Маренкин С.Ф., Трухан В.М. Фосфиды, арсениды цинка и кадмия. г. Минск: издательство «Вараксин». 2010. 224 с.

3. Вайполин А.А. и др. Поляризационные исследования фотопроводимости тетрагональных кристаллов $\mathrm{ZnP}_{2} . / /$ ФТПА; 1980, т.14, вып.1, с. 133...138.

4. Yanuskevicius Z. et a fl / Electrical Hroperties of doped $\alpha-\mathrm{ZnP}_{2}$ singles crystals//Phys/Status Solidi (a). 1980. Vol. 59/2. P.139-142.

5. Горохватский Ю.А., Борзовский Г.А. Термоактивационная токовая спектроскопия высокоомных полупроводников и диэлектриков. М.: изд. «Наука», 1991г., с.248.

6. Шелег А.У., Зарецукий В.В. Исследование последовательности фазовых переходов соизмеримая - несоизмеримая фаза в $\alpha-\mathrm{ZnP}_{2}$ рентгенографическими методами//Письма в ЖЭТФ; 1984. вып.4. С. 166-169.

7. Федотов В.Г. Влияние модулированной структуры на электрические, фотоэлектрические и оптические свойства кристаллов дифосфида цинка и 
кадмия// Збірник наукових праць. Водний транспорт, випуск №1 (24). 2016. С. 185-189.

8. Якимович В.Н., Трухан В.М. Дилатометрические исследования монокриталлов $\mathrm{ZnP}_{2}$ и $\mathrm{CdP}_{2} . / /$ ФТТ, 1995, т.30, вып.4; С. 950-953.

\section{Федотов В.Г., Михеев А.И.}

\section{ВЛИЯНИЕ ЭЛЕКТРИЧЕСКИ АКТИВНЫХ ДЕФЕКТОВ НА}

\section{ТЕРМОСТИМУЛИРОВАННЫЕ ТОКИ В КРИСТАЛЛАХ ДИФОСФИДА ЦИНКА}

Известно, что возрастание электропроводимости в полупроводниковых материалах происходит двумя путями: за счет повышения их температуры, а также посредством роста количества примесей и дефектов в кристаллах этих материалов. C этой точки зрения $\kappa$ перспективным полупроводниковым материалам можно отнести кристалль дифосфида иинка и кадмия. В нашем случае в качестве объекта исследования были выбраны кристалль $\alpha$ - ZnP $P_{2}$ В У тетрагональных кристаллах дифосфида ичинка, которые были выращень методом сублимации в двух температурной печи, выявлены электрически активные дефекты, обусловливающчие появление релаксачионных токов короткого замыкания в проиессе нагрева. Спонтанная поляризация, генерирующая термостимулированные токи короткого замыкания, вызвана нарушениями динамичного равновесия в электронной $и$ решетчатой подсистемах кристалла $\alpha-\mathrm{ZnP}_{2}$.

Ключевые слова: пониженные симметричные кристалль, электрически активные дефекты, термостимулированные токи.

\section{Fedotov V., Mikheev A.}

\section{INFLUENCE OF THE ELECTROACTIVE DEFECTS TO THERMOSTIMULATED} CURRENTS INTO CRYSTALS ZnP 2

Im is known that the increase in electrical conductivity in semiconductor materials occurs in two ways: by increasing their temperature, as well as by increasing the number of impurities and defects in the crystals of these materials. From this point of view, the crystals of zinc diphosphide and cadmium can be attributed to promising semiconductor materials. In our case, crystals of $\alpha-\mathrm{ZnP}_{2}$, which were grown by sublimation in two temperature furnaces, were selected as the object of the study, electrically active defects were identified, causing the appearance of short-circuit relaxation currents during the heating process. Spontaneous polarization, which generates short-circuit thermostimulated currents, is caused by disturbances of dynamic equilibrium in the electronic and lattice subsystems of the crystal of zinc diphosphide.

Keywords: lower symmetric crystals, electroactive defects, thermostimulated currents. 